\title{
Paired copper monomers in zeolite omega: the active site for methane-to-methanol conversion
}

\author{
Amy J. Knorpp, ${ }^{[a]}$ Ana B. Pinar, ${ }^{[b]}$ Christian Baerlocher, ${ }^{[a]}$ Lynne B. McCusker, ${ }^{\left[{ }^{[c]}\right.}$ Nicola Casati, ${ }^{[d]}$ Mark A. \\ Newton, ${ }^{[a]}$ Stefano Checchia, ${ }^{[\mathrm{e}]}{ }^{3}$ Jordan Meyet, ${ }^{[\mathrm{a}]}$ Dennis Palagin, ${ }^{[\mathrm{b}]}$ Jeroen A. van Bokhoven, ${ }^{[a, b]^{*}}$
} \author{
Institute for Chemistry and Bioengineering \\ ETH Zürich \\ Vladimir-Prelog-Weg 1, 8093 Zürich (Switzerland) \\ E-mail: jeroen.vanbokhoven@chem.ethz.ch \\ [b] Dr. A. B. Pinar, Dr. D. Palagin, Prof. Dr. J. A. van Bokhoven \\ Laboratory for Catalysis and Sustainable Chemistry \\ Paul Scherrer Institut \\ 5232 Villigen PSI (Switzerland) \\ [c] Dr. L. B. McCusker \\ Department of Materials \\ ETH Zürich \\ Vladimir-Prelog-Weg 5, 8093 Zürich (Switzerland) \\ [d] Dr. N. Casati \\ Laboratory for Synchrotron Radiation- Condensed Matter \\ Paul Scherrer Institut \\ 5232 Villigen, Switzerland \\ [e] Dr. S. Checchia \\ ID 15A \\ European Synchrotron Radiation Facility \\ 71 Avenue des Martyrs, 38000 Grenoble (France)
}

[a] Dr. A. J. Knorpp, Dr. C. Baerlocher, Dr. M. A. Newton, J. Meyet, Prof. Dr. J. A. van Bokhoven

\begin{abstract}
The direct conversion of methane to methanol using oxygen is a challenging but potentially rewarding pathway towards utilizing methane. By using a stepwise chemical looping approach, copper-exchanged zeolites can convert methane to methanol, but productivity is still too low for viable implementation. However, if the nature of the active site could be elucidated, that information could be used to design more effective catalysts. By employing anomalous Xray powder diffraction with support from theory and other X-ray techniques, we have derived a quantitative and spatial description of the highly selective, active copper sites in zeolite omega (Cu-omega). This is the first comprehensive description of the structure of noncopper-oxo active species and will provide a pivotal model for future
\end{abstract} development for materials for methane to methanol conversion.

The development of chemical systems that can convert methane to methanol directly are of high interest, because methane is a cheap and readily available feedstock that continues to be flared globally on a massive scale (143 billion $\left.\mathrm{m}^{3} / \mathrm{a}\right) \cdot{ }^{[1-3]}$ However, this conversion comes with significant challenges, in particular, overcoming the facile over-oxidation of methanol compared to that of methane. Therefore, strategies and systems that can minimize over-oxidation and optimize productivity are required. ${ }^{[4-}$ 7] One of the most promising and highly investigated approaches involves a chemical looping process over copper-cationexchanged zeolites, where the oxidative activation of the copper is decoupled from the reaction and product evolution. ${ }^{[8]}$

Successful partial oxidation of methane using oxygen relies not only on the storing of oxygen at the active extra-framework copper site, but also on the ability of the zeolite framework to stabilize that active site while simultaneously preventing overoxidization of the product methanol. This can occur very selectively in copper-zeolites, but productivity remains insufficient for industrial implementation. ${ }^{[9]}$ Therefore, a detailed understanding of the active site upon activation in oxygen and of its structure-property relationships are critical to the development of more active and productive materials. Numerous active-site configurations have been proposed,,$^{[8,10-18]}$ but determining the nature of the active site unambiguously or quantifying it directly has not been possible. Instead, proposed active site configurations have come from a combination of several techniques, largely spectroscopic, which are used to infer, rather than determine, the nature and location of the site(s). ${ }^{[16]}$ Despite the debate, all sites that have been identified are copper-oxo species, which form only at high temperatures..$^{[8,10-13,15-18]} A$ pair of monomeric coppers, a precursor to these copper-oxo species, was proposed recently as a potential active site in low-aluminum copper mordenite ${ }^{[19]}$ and in non-microporous systems derived from the grafting of copper onto alumina. ${ }^{[20]}$ Such an active site would have favorable implications regarding minimizing the activation temperature during pre-treatment, and therefore opens up possibilities for the use of new supports. However, the nature of these monomers is unknown, and more importantly, the local environment which is needed to stabilize these monomers is unknown. By exploiting anomalous X-ray diffraction (AXPD) to highlight the copper species and their relation to the crystal structure, we have achieved the most unequivocal assignment of the active sites in methane-to-methanol conversion to date. We identify, both directly and quantitatively, a pair of copper hydroxide monomers, i.e. a non-copper-oxo species, as the active site in zeolite omega, thus giving unprecedented and holistic structureproperty information that can serve as a guide for future development of materials for the methane-to-methanol reaction.

In methane-to-methanol conversion, copper-cation exchanged zeolite omega (framework type code MAZ, Figure $1)^{[21]}$ can achieve high selectivity (no detectable products of over-oxidation observed by FTIR) and methanol yields for both high (723K) and low (473K) activation temperatures with methanol yields of $200 \mu \mathrm{mol} / \mathrm{gram}$-zeolite, and $141 \mu \mathrm{mol} / \mathrm{gram}$ zeolite respectively. ${ }^{[22,23]}$ The reason behind this superior 
a)

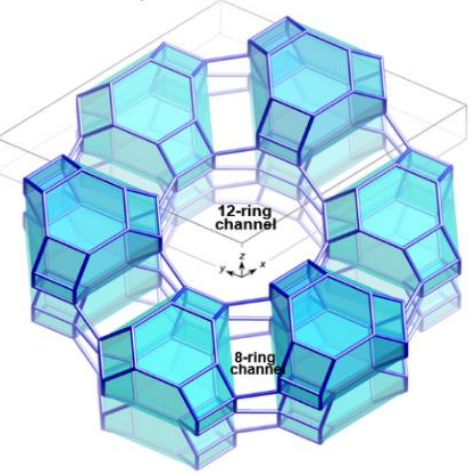

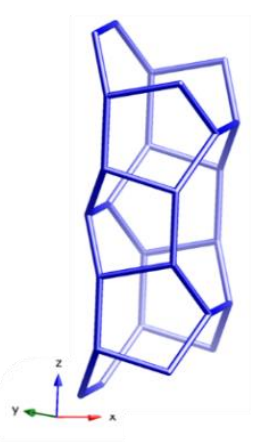

c)

Stepwise conversion

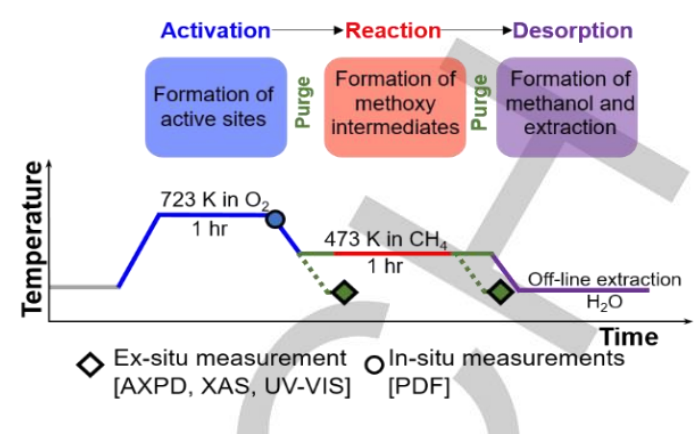

Figure 1: Zeolite omega framework and the stepwise conversion procedure (a) The framework structure of zeolite omega can be viewed as a hexagonal array of stacks of $g$ me cavities $^{[31]}$ (blue) arranged in a staggered fashion to create large one-dimensional 12-ring channels and narrow 8-ring channels running between the gme cavities. (b) A side view of the narrow 8-ring channel showing the staggered arrangement of the 8-rings from adjacent gme cavities. Bridging framework oxygen atoms have been omitted for clarity. (c) Scheme for the stepwise conversion of methane to methanol over copper zeolites. The circles and diamonds indicate the points where measurements in this work were performed.

performance must lie in the details of the zeolite's framework structure and the active sites that it stabilizes. Therefore, a sample (Cu-omega, 4.4 wt.\% copper, $\mathrm{Si} / \mathrm{Al}=4.3$ ) was treated using the stepwise procedure shown in Figure 1c, which also indicates the conditions under which measurements were made and the characterization techniques applied. The primary technique in this work is AXPD, while X-ray absorption spectroscopy (XAS), UVVIS spectroscopy (UV-VIS), and total X-ray scattering/pair distribution function analysis (PDF) were used to confirm/supplement the results from the AXPD analyses.

Two sealed capillaries were prepared for ex-situ measurements. The first capillary contained Cu-omega in its activated state $\left(\mathrm{Cu}_{-} \mathrm{O}_{2} \_723 \mathrm{~K}\right)$, the capillary having been sealed after activation in 1 bar oxygen at $723 \mathrm{~K}$ for 1 hour. The second contained the reacted state of $\mathrm{Cu}$-omega $\left(\mathrm{Cu}_{-} \mathrm{CH}_{4} \_473 \mathrm{~K}\right)$, obtained by exposure of the activated Cu-omega to methane at 1 bar for 1 hour at 473K. Synchrotron powder diffraction data were then collected on these two samples at room temperature at three different wavelengths $(0.7105 \AA, 1.3805 \AA$ and $1.3818 \AA$ ) on the Materials Science Beamline at the Swiss Light Source (SLS). ${ }^{[24]}$ These measurements, far from, just below and just above the copper K-edge, respectively, allow copper ions to be identified unambiguously within the zeolite omega structure. The same capillaries were measured with XAS at the $\mathrm{Cu} \mathrm{K}$-edge on the SuperXAS Beamline ${ }^{[25]}$ at SLS to obtain complementary EXAFS spectra and to confirm that no moisture had leaked into the capillaries. Crystallographic data, cif files, selected distances and angles, the profile fits from the Rietveld refinement, along with the XAS spectra and their analysis are provided in supplementary information.

The initial refinement of the structure of $\mathrm{Cu}_{1} \mathrm{O}_{2} \_723 \mathrm{~K}$ was performed using the $0.7105 \AA$ (off-edge) data and the framework structure of zeolite omega (MAZ) ${ }^{[21]}$ in the space group $P 6_{3} / \mathrm{mmc}$. A series of difference electron density maps revealed three locations for the copper: $\mathrm{Cu}(1)$ in the 6-ring, and $\mathrm{Cu}(2)$ and $\mathrm{Cu}(3)$ in the gme-cavity 8-ring (see Figure 2). A further peak between the 8-rings of adjacent gme cavities, was found in a subsequent difference electron density map and was added to the model as extra-framework oxygen, $(\mathrm{O}(10))$. A full refinement of all positional and profile parameters was then performed using all three data sets simultaneously, confirming the copper position assignments.

The occupancies of the three copper positions refined to $0.56,0.78$ and $0.80 \mathrm{Cu}^{2+}$ per unit cell and that of $\mathrm{O}(10)$ to $1.62 \mathrm{O}$ atoms per unit cell. The electron density of the $\mathrm{O}(10)$ position was somewhat elongated, so it was split into $O(10)$ and $O(11)$, each with half the previous occupancy, and these positions and occupancies proved to be stable in refinement. All equivalent positions of the extra-framework atoms are shown in Figure S1. There are $6 \mathrm{Cu}(1), 12 \mathrm{Cu}(2), 12 \mathrm{Cu}(3), 12 \mathrm{O}(10)$ and $12 \mathrm{O}(11)$ symmetry equivalent positions per unit cell, but only a small fraction of them (less than one) are occupied in any given unit cell (approximately $0.5 \mathrm{Cu}(1), 0.75 \mathrm{Cu}(2), 0.75 \mathrm{Cu}(3), 0.75 \mathrm{O}$ (10) and $0.75 \mathrm{O}(11)$ per unit cell). A selection of positions reflecting a possible arrangement of the $\mathrm{Cu}^{2+}$ ions at $\mathrm{Cu}(1), \mathrm{Cu}(2)$ and $\mathrm{Cu}(3)$, is shown in Figure 2. The $\mathrm{Cu}^{2+}$ ions at $\mathrm{Cu}(1)$ in the 6-ring are offcenter and coordinate to four framework oxygen atoms (two at $\mathrm{O}(61)$ and two at $\mathrm{O}(5))$ in the plane of the 6-ring. Only about one 6-ring in four is occupied. The $\mathrm{Cu}^{2+}$ ions at $\mathrm{Cu}(2)$ in the 8-ring bond to framework oxygen atoms at $\mathrm{O}(6)$ at $1.90 \AA$ and approach two more at $\mathrm{O}(2)$ at $2.22 \AA$. The non-framework oxygen atom at $\mathrm{O}(11)$ completes a distorted square planar coordination around the $\mathrm{Cu}^{2+}$ ion. The $\mathrm{Cu}^{2+}$ ions at $\mathrm{Cu}(3)$ bond to framework oxygen atoms at $\mathrm{O}(4)$ at $1.88 \AA$ and to the non-framework oxygen atom at $\mathrm{O}(10)$ at $1.89 \AA$. The latter has two possible positions. It could act as a bridge to the $\mathrm{Cu}^{2+}$ ion at $\mathrm{Cu}(2)$ at $1.89 \AA$, making the $\mathrm{Cu}^{2+}$ coordination at $\mathrm{Cu}(2)$ square pyramidal (as shown in Figure 2), or it could point in the other direction down the narrow 8-ring channel, where it is still $1.89 \AA$ from $\mathrm{Cu}(3)$ but not associated with $\mathrm{Cu}(2)$. With either arrangement, the $\mathrm{Cu}^{2+}$ ions at $\mathrm{Cu}(2)$ and $\mathrm{Cu}(3)$ are $3.45 \AA$ apart, and these coppers appear to exist as two proximal $\mathrm{Cu}[\mathrm{OH}]^{+}$monomers.

The Rietveld refinement shows two copper sites in the 8ring, but the occupancy per unit cell is low and their distribution over the available symmetry-equivalent sites cannot be determined directly. To establish whether these coppers are paired across the narrow 8-ring channel, and work in tandem, exsitu EXAFS from the activated sample and in-situ PDF were analyzed (see supplementary information). The EXAFS fits confirm the presence of a copper-copper distance at 3.4 $\AA$. A PDF derived from in-situ experiments at $723 \mathrm{~K}$ in oxygen results in a consistent viewpoint with a copper-copper pair distance at $3.3 \AA$. Thus confirming that these two coppers identified by AXPD do indeed exist in 8-rings of adjacent gme cavities, where they can interact with one another across the narrow 8-ring channel, and thereby facilitate the two-electron redox mechanism for the conversion of methane to methanol.[26] 

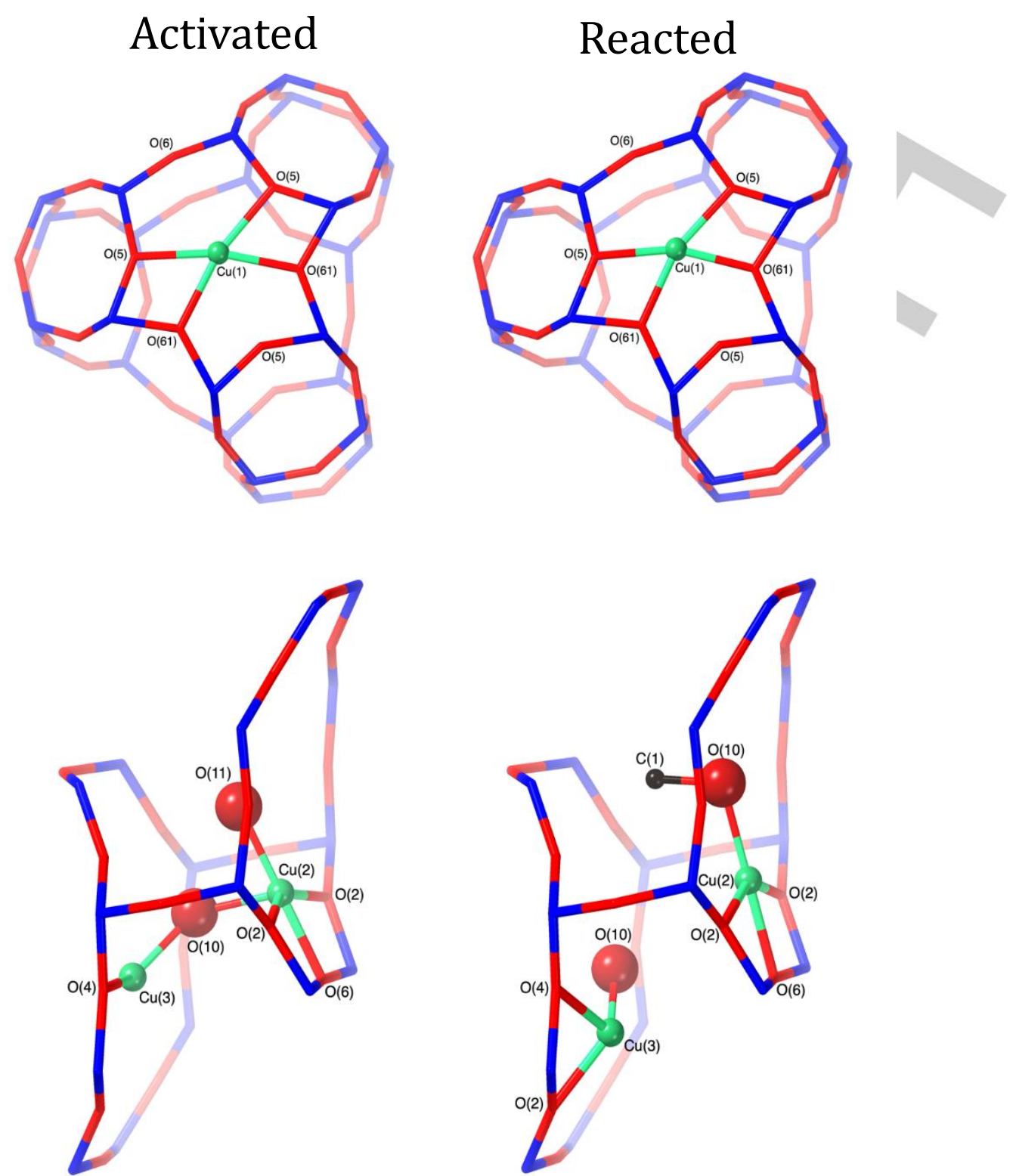

Figure 2: Structures of $\mathrm{Cu}_{-} \mathrm{O}_{2}$ 723K and $\mathrm{Cu}_{-} \mathrm{CH}_{4}$-473K. (top) Coordination of the $\mathrm{Cu}^{2+}$ ions at $\mathrm{Cu}(1)$ in a 6-ring of a gme cavity showing the difference between an occupied (front) and an unoccupied (back) 6-ring, and (bottom) coordination geometries of $\mathrm{Cu}(2)$ and $\mathrm{Cu}(3)$ before and after the introduction of $\mathrm{CH}_{4}$.

Further confirmation is evident from the refinement of the structure of the reacted sample $\left(\mathrm{Cu}_{-} \mathrm{CH}_{4} \_473 \mathrm{~K}\right)$. Refinement was initiated by using just the $0.7105 \AA$ data and the framework structure for the activated material. $\mathrm{Cu}(1)$ was unaltered by the reaction step, as expected. ${ }^{[27-29]}$ However, changes were observed in the coppers in the 8-ring (Figure 2, bottom right). Specifically, $\mathrm{Cu}(3)$ moved from its position on the horizontal mirror plane to one where it can interact with two rather than just one framework oxygen and is further away from $\mathrm{Cu}(2)$. Only one extraframework oxygen position was apparent $(\mathrm{O}(10))$, with one of its equivalent positions located $1.99 \AA$ from $\mathrm{Cu}(2)$ and a different one $1.90 \AA$ from $\mathrm{Cu}(3)$. Finally, a peak close to $\mathrm{O}(10)$ appeared in a difference electron density map, and it was added as $\mathrm{C}(1)$. These extra-framework oxygen and carbon atoms probably constitute the adsorbed methane conversion intermediate, the methoxy $\left[\mathrm{Cu}^{1+}-\mathrm{OCH}_{3}\right]$ species. This intermediate species has previously been observed by $\mathrm{C}^{13} \mathrm{CP} / \mathrm{MAS}$ NMR in low-aluminum content mordenite ${ }^{[30]}$, which also contains paired monomer active sites.
These methoxy species goes on to form methanol in the extraction step, and corroborates the hypothesis that the reaction is taking place between the coppers on either side of the narrow 8-ring channel where methane has to diffuse through the convoluted 3-dimensional 8-ring channel system to reach the active sites.

As with the activated sample, the other two $\mathrm{Cu}_{-} \mathrm{CH}_{4} \_473 \mathrm{~K}$ data sets were then included in further refinement. The copper ions at $\mathrm{Cu}(1)$ were assumed to correspond to the unreactive ones, and were refined as $\mathrm{Cu}^{2+},{ }^{[27,29]}$ while those at $\mathrm{Cu}(2)$ and $\mathrm{Cu}(3)$ were refined as $\mathrm{Cu}^{1+}$, as it has been previously shown that two copper reductions are correlated with each methanol molecule formed. ${ }^{[26]}$ Occupancy parameters for the three copper positions were similar to those found in the $\mathrm{Cu}_{-} \mathrm{O}_{2}$ 723K structure. The occupancy of $\mathrm{O}(10)$ refined consistently to values close to the sum of the occupancies of $\mathrm{Cu}(2)$ and $\mathrm{Cu}(3)$, and that of carbon $\mathrm{C}(1)$ somewhat lower. In the final structural model then, the occupancies of $\mathrm{Cu}(2)$ and $\mathrm{Cu}(3)$ were constrained to be equal, 


\begin{tabular}{|c|c|c|c|}
\hline \multirow{2}{*}{$\begin{array}{c}{[\mathrm{Cu}-\mathrm{OH}]^{+} \ldots . . . . .[\mathrm{Cu}-\mathrm{OH}]^{+}} \\
{[\mathrm{Cu}-\mathrm{OH}]^{+}+.[\mathrm{Cu}-\mathrm{OH}]^{+}}\end{array}$} & \multirow{6}{*}{ 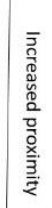 } & & \\
\hline & & Characterization method & $\begin{array}{l}\text { Cu(2)-Cu(3) } \\
\text { Distance [Â] }\end{array}$ \\
\hline \multirow{5}{*}{$\mathrm{Cu}^{-\mathrm{OH}}=\left[\mathrm{Cu}^{\mathrm{H}} \mathrm{OH}\right.$} & & AXPD & 3.45 \\
\hline & & EXAFS & 3.4 \\
\hline & & PDF & 3.3 \\
\hline & & DFT & 3.25 \\
\hline & & Molecular dynamics & $2.9-3.5$ \\
\hline
\end{tabular}

Figure 3: Copper-Copper proximity (Left) Proposed species as proximity of $[\mathrm{Cu}-\mathrm{OH}]^{+}$monomers increases. Since the molecular dynamic simulation shows that the distance between the coppers can oscillate dynamically, a dashed line is drawn between the two copper to represent this potential oscillation. (Right) Distances of the copper-copper interaction according to different methods (this work).

that of $\mathrm{O}(10)$ to be twice that of $\mathrm{Cu}(2)$, and that of $\mathrm{C}(1)$ to be 1.5 times (to account for the three electrons from $\mathrm{H}$ in $\mathrm{CH}_{3}$ ) that of $\mathrm{Cu}(2)$. All equivalent positions of the extra-framework atoms are shown in Figure S1, and a selection of these positions reflecting a possible arrangement is shown in Figure 2.

From the results of the refinement of the occupancies and positions of these extra-framework species, we can now specify the nature and geometry of the active copper site, how the zeolite omega framework affects the nature and geometry of this site, and how these arrangements lead to the selective conversion of methane. It appears that maintaining a stable distance between the monomers is critical, and this proximity is defined by the zeolite's framework structure-in particular, the geometry of the narrow 8-ring channels. The proximity of the copper ions to one another may result in a weak interaction between the two [Cu$\mathrm{OH}]^{+}$species, causing $\mathrm{Cu}(3)$ to move in the gme 8-ring as suggested by the refinement. DFT modelling shows that if these monomers are too close together, they will form a dimer with two bridging hydroxyl groups, while in the 8-ring channels of $\mathrm{Cu}$ omega, proximal monomers can form stable associated pairs. Molecular dynamics simulation of these proximal monomers at $723 \mathrm{~K}$ provides a glimpse of how these monomers interact. The copper hydroxide maintains its monomeric character, but the distance between the $\mathrm{Cu}(2)$ and the $\mathrm{Cu}(3)$ may oscillate, and these two monomers can loosely interact (Figure S6). The average $\mathrm{Cu}(2)-\mathrm{Cu}(3)$ distances derived from the different characterization methods are provided in Figure 3.

Cu-omega is one of the most selective and highest methanol-yielding zeolite systems for the stepwise conversion of methane to methanol. From the measurements reported here, it is clear that this results directly from a framework topology that can stabilize paired $[\mathrm{CuOH}]^{+}$monomers at specific sites with a relatively high density. By refining the occupancies and locations of all extra-framework species using X-ray powder diffraction techniques, one of the first holistic views of an active copper speciation and its location in the zeolite structure has been achieved. Furthermore, the unprecedented and precise information that we have derived provides a blueprint for a local arrangement of proximal monomers that can be applied beyond zeolites to other non-microporous supports. Just as the development of copper-exchanged zeolites for methane-tomethanol conversion has been bio-inspired from coppercontaining enzymes, the elucidation of the active site and relevant structural properties in zeolite omega, presented here, can lead to the next generation of zeolite-inspired materials for methaneto-methanol conversion.

\section{Acknowledgements}

DP gratefully acknowledges the use of computational facilities provided by the Swiss National Supercomputing Centre. We thank Prof. Coperet for use of the UV-Vis spectrometer, Dr. Nachtegaal for assistance at the SuperXAS beamline, Dr. Sushkevich for capillary sealing, Dr. Rzepka for discussions of copper in zeolites, and Dr. Calbry-Muzyka for English editing. We would also like to thank SLS for giving us access to the material science and the SuperXAS beamlines.

Keywords: copper zeolites $\cdot$ methane $\cdot$ zeolite omega • methanol $\cdot$ anomalous $X$-ray diffraction

[1] E. G. Nisbet, E. J. Dlugokencky, P. Bousquet, Science 2014, 343, 493-496.

[2] C. D. Elvidge, M. Zhizhin, K. Baugh, F. C. Hsu, T. Ghosh, Energies 2016, 9, 14.

[3] Y. Zhang, R. Gautam, S. Pandey, M. Omara, J. D. Maasakkers, P. Sadavarte, D. Lyon, H. Nesser, M. P. Sulprizio, D. J. Varon, R. Zhang, S. Houweling, D. Zavala-araiza, R. A. Alvarez, A. Lorente, S. P. Hamburg, I. Aben, D. J. Jacob, Sci. Adv. 2020, 2007, 1-10.

[4] M. Ahlquist, R. J. Nielsen, R. A. Periana, W. A. Goddard, J. Am Chem. Soc. 2009, 131, 17110-17115.

[5] A. A. Latimer, A. Kakekhani, A. R. Kulkarni, J. K. Nørskov, ACS Catal. 2018, 8, 6894-6907.

[6] Z. Jin, L. Wang, E. Zuidema, K. Mondal, M. Zhang, J. Zhang, C Wang, X. Meng, H. Yang, C. Mesters, F. S. Xiao, Science 2020, 367, 193-197.

[7] C. Díaz-Urrutia, T. Ott, Science 2019, 363, 1326-1329.

[8] M. H. Groothaert, P. J. Smeets, B. F. Sels, P. A. Jacobs, R. A. Schoonheydt, J. Am. Chem. Soc. 2005, 127, 1394-1395. Z. R. Jovanovic, J.-P. Lange, M. Ravi, A. J. Knorpp, V. L. Sushkevich, M. A. Newton, D. Palagin, J. A. van Bokhoven, J. Catal. 2020, 385, 238-245.

[10] J. S. Woertink, P. J. Smeets, M. H. Groothaert, M. A. Vance, B. F. Sels, R. A. Schoonheydt, E. I. Solomon, Proc. Natl. Acad. Sci. 2009, 106, 18908-18913.

[11] P. Vanelderen, B. E. R. Snyder, M. L. Tsai, R. G. Hadt, J. Vancauwenbergh, O. Coussens, R. A. Schoonheydt, B. F. Sels, E. I. Solomon, J. Am. Chem. Soc. 2015, 137, 6383-6392.

[12] E. M. C. Alayon, M. Nachtegaal, A. Bodi, M. Ranocchiari, J. A. van Bokhoven, Phys. Chem. Chem. Phys. 2015, 17, 7681-7693.

[13] S. Grundner, M. A. C. Markovits, G. Li, M. Tromp, E. A. Pidko, E. J. M. Hensen, A. Jentys, M. Sanchez-Sanchez, J. A. Lercher, Nat. Commun. 2015, 6, 7546.

[14] A. R. Kulkarni, Z. J. Zhao, S. Siahrostami, J. K. Nørskov, F. Studt, ACS Catal. 2016, 6, 6531-6536.

[15] B. Ipek, M. J. Wulfers, H. Kim, F. Göltl, I. Hermans, J. P. Smith, K. S. Booksh, C. M. Brown, R. F. Lobo, ACS Catal. 2017, 7, 42914303.

[16] M. A. Newton, A. J. Knorpp, V. L. Sushkevich, D. Palagin, J. A. van Bokhoven, Chem. Soc. Rev. 2020, 49, 1449-1486.

[17] D. K. Pappas, A. Martini, M. Dyballa, K. Kvande, S. Teketel, K. A. Lomachenko, R. Baran, P. Glatzel, B. Arstad, G. Berlier, C. Lamberti, S. Bordiga, U. Olsbye, S. Svelle, P. Beato, E. Borfecchia, 
J. Am. Chem. Soc. 2018, 140, 15270-15278.

[18] B. E. R. Snyder, P. Vanelderen, R. A. Schoonheydt, B. F. Sels, E. I. Solomon, J. Am. Chem. Soc. 2018, 140, 9236-9243.

[19] V. L. Sushkevich, D. Palagin, J. A. van Bokhoven, Angew. Chemie Int. Ed. 2018, 57, 8906-8910.

[20] J. Meyet, K. Searles, M. A. Newton, M. Wörle, A. P. van Bavel, A. D. Horton, J. A. van Bokhoven, C. Coperet, Angew. Chemie 2019, 58, 9841-9845.

[21] C. Baerlocher, L. B. McCusker, "Database of Zeolite Structures:," can be found under http://www.iza-structure.org/databases/, n.d. A. J. Knorpp, A. B. Pinar, M. Newton, V. Sushkevich, J. A. van Bokhoven, ChemCatChem 2018, 10, 5593-5596.

[23] A. J. Knorpp, M. A. Newton, S. C. M. Mizuno, J. Zhu, H. Mebrate, A. B. Pinar, J. A. Van Bokhoven, Chem. Commun. 2019, 55, 1179411797.

[24] P. R. Willmott, D. Meister, S. J. Leake, M. Lange, A. Bergamaschi, M. Boege, M. Calvi, C. Cancellieri, N. Casati, A. Cervellino, Q. Chen, C. David, U. Flechig, F. Gozzo, B. Henrich, S. JaeggiSpielmann, B. Jakob, I. Kalichava, P. Karvinen, J. Krempasky, A. Luedeke, R. Luescher, S. Maag, C. Quitmann, M. L. Reinle-Schmitt, T. Schmidt, B. SChmitt, A. Streun, I. Vartianinen, M. Vitins, X. Xang, R. Wullschleger, J. Synchrotron Radiat. 2013, 20, 667-682.

[25] O. Müller, M. Nachtegaal, J. Just, D. Lützenkirchen-Hecht, R. Frahm, J. Synchrotron Radiat. 2016, 23, 260-266.

[26] M. A. Newton, A. J. Knorpp, A. B. Pinar, V. L. Sushkevich, D. Palagin, J. A. Van Bokhoven, J. Am. Chem. Soc. 2018, 140, 1009010093.

[27] P. J. Smeets, J. S. Woertink, B. F. Sels, E. I. Solomon, R. A. Schoonheydt, Inorg. Chem. 2010, 49, 3573-3583.

[28] P. Vanelderen, J. Vancauwenbergh, B. F. Sels, R. A. Schoonheydt, Coord. Chem. Rev. 2013, 257, 483-494.

[29] D. K. Pappas, E. Borfecchia, M. Dyballa, I. A. Pankin, K. A. Lomachenko, A. Martini, M. Signorile, S. Teketel, B. Arstad, G. Berlier, C. Lamberti, S. Bordiga, U. Olsbye, K. P. Lillerud, S. Svelle, P. Beato, J. Am. Chem. Soc. 2017, 139, 14961-14975.

[30] V. L. Sushkevich, R. Verel, J. A. van Bokhoven, Angew. Chemie Int. Ed. 2020, 59, 910-918.

[31] L. B. McCusker, F. Liebau, G. Englehardt, Pure Appl. Chem. 2001, 73, 381-394. 


\section{WILEY-VCH}

\section{COMMUNICATION}

\section{Entry for the Table of Contents}

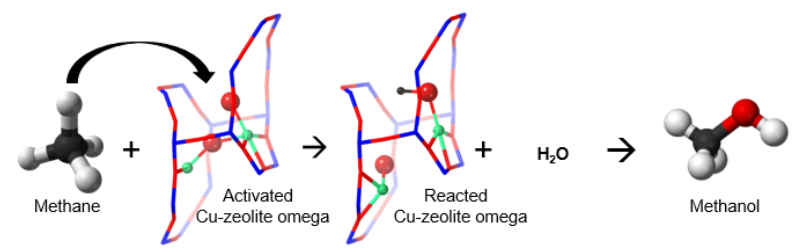

By employing anomalous X-ray powder diffraction along with support from theory and other X-ray techniques, the active copper site for methane-to-methanol conversion in zeolite omega has been determined spatially and quantitatively. 